\title{
(3) eleifmort
}

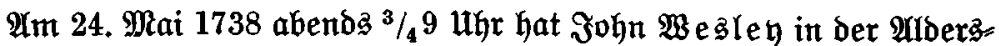
gate Street zu Ronbon jenes (Exlebnis gehabt, bas für ben Methodiss: mus grundlegend geworden ijt: er wurde bon ber (Serwipheit bes in Ehrijto erworbenen und angebotenen $\mathfrak{b e i l s ~ u ̈ b e r w a ̈ l t i g t , ~ u n d ~ z w a r ~ g e = ~}$

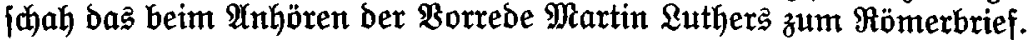
Wo immer in ber Welt am 24. Mai biejes Jahres Methodipten jener eigentlichen Geburtsitunde ihrer Sonfeffion gebachten, 一 und ber

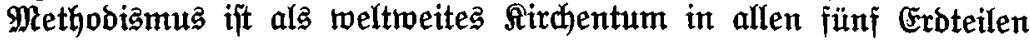

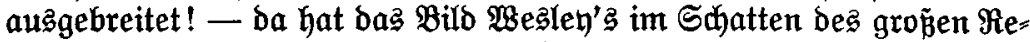
formators geftanden. Quthers Beitalt ift notwendigerweije mit babei gervejen. Im beutiden $\mathfrak{Z}$ uthertum hat man ben $\mathfrak{I a g}$ aud nidht ver=

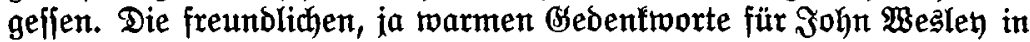
beutjaben ebangelijhen Beitjchriften beweijen, bá guter wille zum Berftändnis ber anderätonfeffionellen $\mathfrak{A} x$ auch bei uns ba ijt.

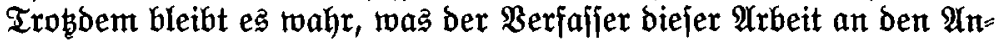

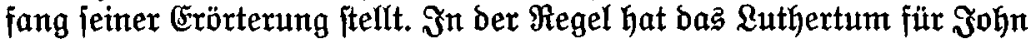
Wesley leine Gympathien betundet, oft ihn abgelehnt und betämpit. Da nun aber in ber englifich fprechenden $\mathfrak{B}$ elt ber Methodismus auf

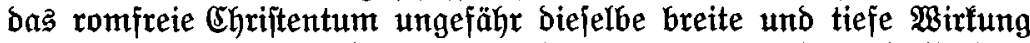
auggeübt hat und biejelbe typifierende Bebeutung befizt, wie fie bem Suthertum innerhalb bes $\mathfrak{B o l f 3 b e u t j h t u m s ~ z u f o m m t , ~ f o ~ l a n n ~ b i e ~ T a t ~}$

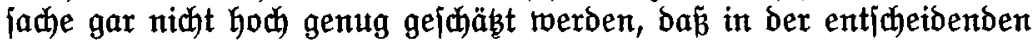

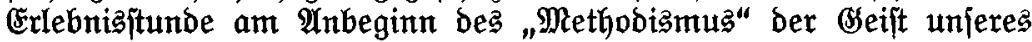
Reformators Bate geftanden hat. Weld eine weife Fügung ber (Se= jabidyte unb welch eine bauende Mahnung an ung ! Bejinnen fid Mie= thodiften auf ihr Eigenftes, jo müffen jie an ein Urerlebnis benfen, bas ohne $\mathfrak{Q u t h e r ~ f e i n e n ~ ( S e h a l t ~ h a ̈ t t e . ~ U n d ~ l a u j d j e n ~ l u t h e r i j d e ~ ( o h r i f t e n ~ a u f ~}$

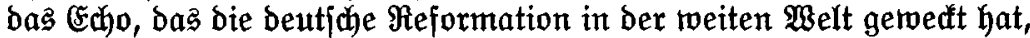
jo gibt es $\mathfrak{l}$ aum einen ftärferen und reineren Ton bes Wiberhalls, als wix ifn an $̧ o h n$ wesley vernehmen.

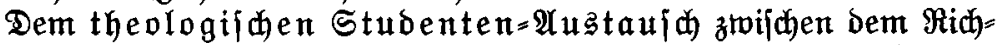

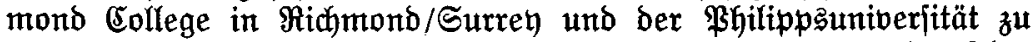
Marburg berdanten wir bereits eine gelehrte 2 bhandung aus beutjoher Feder. (\$n biejer Reihe BD. 16 Martin Dietrid): "Theologijde Dnto=

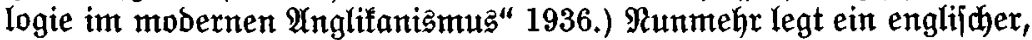

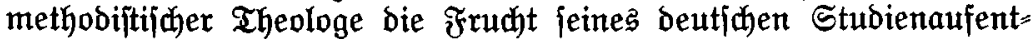
haltes vor. (Es bürite fiđ exübrigen, über bie Schrierigfeiten uno

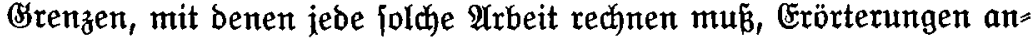
zuftellen. Sebem, ber aud nur oberflählich bie beiben Sonfeffionen 


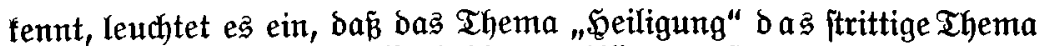

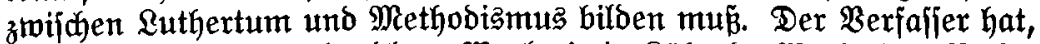

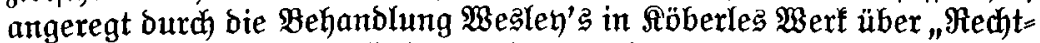

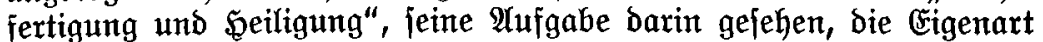

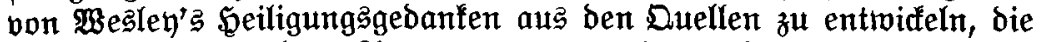
bagegen borgebradjten $\mathfrak{A}$ rgumente zu prïfen und ben Radbweis zu

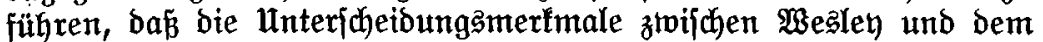
Quthertum beffer verftändlich weroen, fobald man mit $\mathfrak{B e s l e y ~ z w a r ~}$

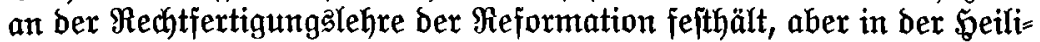
gungalehre entichiedener als die Butheraner zum Reuen Teftament zurürffehrt.

Das wohlabgetwogene Grgebnis, z̆ dem ber Berfaffer fommt, fowie

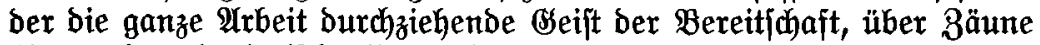
hinweg bas theologijde Bejpräch zu führen, berechtigen bazu, bieje von ber Miarburger Theologifahen Fafultät als Differtation anerfannte

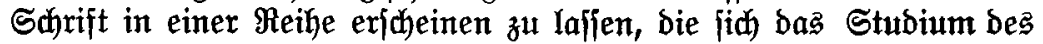

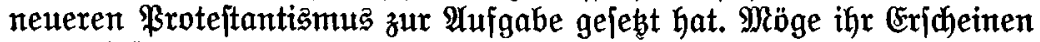
bem tiejeren gegenjeitigen Beritehen zrwijhen methodiftijd)er und lutherifder Theologie zugute fommen! Möge fie barïber hinaus ben geiftigen und geiftlidjen Sontaft zwijhen Dem beutichen und bem eng= lifchen ßroteitantißmus fördern!

Marburg/Lahn, am I. Weifnadjtatag 1938 